\title{
Proton pump inhibitors enhance chemosensitivity, promote apoptosis, and suppress migration of breast cancer cells
}

\author{
WOROOD G. IHRAIZ \\ MAMOUN AHRAM ${ }^{2}$ \\ SANAA K. BARDAWEEL ${ }^{1, *}$ \\ ${ }^{1}$ Department of Pharmaceutical \\ Sciences, School of Pharmacy \\ University of Jordan, Amman 11942 \\ Jordan \\ ${ }^{2}$ School of Medicine, The University \\ of Jordan, Amman, Jordan
}

\begin{abstract}
Breast cancer is the most common cancer and is the leading cause of cancer deaths among women worldwide. Despite the availability of numerous therapeutics for breast cancer management, cytotoxicity and emergence of drug resistance are major challenges that limit their benefits. The acidic microenvironment surrounding tumor cells is a common feature inducing cancer cell invasiveness and chemoresistance. Proton pump inhibitors (PPIs) are one of the most commonly prescribed drugs for the treatment of acid-related conditions. PPIs have been reported to exhibit antitumorigenic effects in many cancer types. In this study, the anti-proliferative and anti-migratory effects of PPIs in three breast cancer cell lines; MCF-7, T47D, and MDA-MB-231 cells, have been investigated. In addition, the combined effects of PPIs with anticancer drugs, as well as the mechanism of PPImediated anti-proliferative activity were evaluated. The antiproliferative and combined effects of PPIs were evaluated by MTT assay. Cell migration was assessed using the wound-healing assay. The mechanism of cell death was assessed using annexin V-FITC/ propidium iodide staining flow cytometry method. Our results indicated that PPIs treatment significantly inhibited the growth of breast cancer cells in a dose-dependent manner. The antiproliferative activity of PPIs was significantly induced by apoptosis in all tested cell lines. The combined treatment of PPIs with doxorubicin resulted in a synergistic effect in all cell lines, whereas the combined treatment with raloxifene exhibited synergistic effect in T47D cells only and additive effects in MDA-MB-231 and MCF-7 cells. In addition, PPIs treatment significantly reduced cell migration in MDA-MB-231 cells. In conclusion, the addition of PPIs to the treatment regimen of breast cancer appears to be a promising strategy to potentiate the efficacy of chemotherapy and may suppress cancer metastasis.
\end{abstract}

Keywords: proton pump inhibitors, breast cancer, chemosensitivity, apoptosis, metastasis

Breast cancer is the most common type of cancer among female worldwide (1). The incidence rates of breast cancer are increased with age in the majority of cases diagnosed

\footnotetext{
* Correspondence; e-mail: S.Bardaweel@ju.edu.jo
} 
after the age of 40 years (2). Unfortunately, despite the continued development of many breast cancer therapies, toxicity and emerging of drug resistance are commonly encountered challenges (3). These phenomena are partly due to the highly heterogeneous nature of the disease at both inter-tumor and intra-tumor level (4).

There is accumulating evidence supporting the role of acidic tumor microenvironment in tumor development and progression $(5,6)$. Metastasis, invasiveness, and chemoresistance have been shown to be associated with tumor acidic microenvironment (5-7). Moreover, extracellular acidity suppresses the activity of immune cells, like the cytotoxic T lymphocytes and natural killer cells protecting cancer cells from the immune system ( 8 , 9). The deviant extracellular acidity is maintained by the overexpression of different ion/ proton pumps including the vacuolar- $\mathrm{H}^{+}$-ATPase (V-ATPase) pumps, which extrude intracellular protons to the extracellular space. Thus, targeting such pump has been considered as a promising strategy to deteriorate cancer cells and reduce tumor metastasis (10).

Numerous pharmacological agents have been used to inhibit the activity of the VATPase pump; however, the clinical application is limited due to their cytotoxicity to normal cells (10). Proton pump inhibitors (PPIs), such as lansoprazole and omeprazole, are the most frequently prescribed drugs for the treatment of acid-related disorders. They specifically target the gastric proton pump $\left(\mathrm{H}^{+}, \mathrm{K}\right.$-ATPase pump) that is located in the gastric parietal cells (11). PPIs also act as V-ATPase inhibitors, suggesting that they may affect the tumor acidic microenvironment (10). In fact, they have been shown to inhibit cancer progression and metastasis and reduce drug resistance in several types of cancers including breast, gastric, colorectal, esophageal, and pancreatic cancers (12-16).

Interestingly, it was initially suggested that the anticancer effect of PPIs is primarily related to their ability to block the V-ATPase pump (10). However, several other mechanisms that contribute to their anticancer activity have been proposed and investigated including suppression of the Wnt/ $\beta$-catenin (17), mammalian target of rapamycin (mTOR), hypoxia-inducible factor 1-alpha (HIF-1 $\alpha$ ), and others $(15,18,19)$.

In the current study, the effects of different PPIs on the viability, migration, and apoptosis of breast cancer cell lines of different molecular subtypes were evaluated. The ability of PPIs to enhance the antitumor effect of other anticancer drugs was also assessed as well as the underlying molecular mechanism driving the antiproliferative effect of PPIs.

\section{EXPERIMENTAL}

\section{Chemicals}

Lansoprazole, omeprazole, pantoprazole, and raloxifene were purchased from SigmaAldrich (USA) as powder and dissolved in DMSO. They were further diluted with Dulbecco's Modified Eagle Medium to reach the desired final concentrations immediately before use. Doxorubicin hydrochloride was purchased from Ebewe Untrerach (Austria) as a solution at a concentration of $2 \mathrm{mg} \mathrm{mL}^{-1}$. MTT (3-[4,5-dimethylthiazol-2-yl]-diphenyltetrazolium bromide) was purchased from Sigma-Aldrich (USA).

\section{Cell lines}

Human MDA-MB-231, MCF-7, and T47D breast cancer cell lines were obtained from the American Type Culture Collection (ATCC) (USA). These cells were maintained in high 
glucose Dulbecco's Modified Eagle Medium (DMEM) (Eurobio, French) supplemented with $10 \%$ fetal bovine serum (FBS), $100 \mathrm{U} \mathrm{mL}^{-1}$ penicillin, $100 \mu \mathrm{g} \mathrm{mL} \mathrm{m}^{-1}$ streptomycin, and $2 \mathrm{mmol} \mathrm{L}{ }^{-1} \mathrm{~L}$-glutamine and were incubated at $37^{\circ} \mathrm{C}$ in a $95 \%$ humidified air of $5 \% \mathrm{CO}_{2}$.

\section{Cell viability assay}

In order to evaluate cell viability, the MTT (3-[4,5-dimethylthiazol-2-yl]-diphenyltetrazolium bromide) colorimetric assay was performed as previously described (20). Briefly, T47D, MCF-7, and MDA-MB-231 cells were plated in a 96-well plate at a seeding density of 8,000, 7,000, 5000 cells per well, respectively. After $24 \mathrm{~h}$, they were treated with different concentrations of PPIs, doxorubicin, and raloxifene alone or in combination. After $48 \mathrm{~h}$, MTT was added at a working concentration of $5 \mathrm{mg} \mathrm{mL}^{-1}$ and incubated for $3 \mathrm{~h}$. Media were then aspirated, and formazan crystals were solubilized in DMSO. The optical density was measured at $570 \mathrm{~nm}$ using the Synergy HTX Multi-Mode Microplate Reader (BioTek Instruments, Winooski, VT, USA). The percentage of cell viability was calculated according to the following equation:

cell viability $(\%)=($ optical density of treated cells/optical density of untreated cells $) \times 100$

\section{Migration assay}

MDA-MB-231 cells were plated at a seeding density of 15,000 cells per insert well (Ibidi, Germany) and incubated overnight to grow to confluency. Afterward, inserts were removed, and cells were treated with $10 \mu \mathrm{g} \mathrm{mL}^{-1}$ of mitomycin C for $2 \mathrm{~h}$. Cells were treated with PPIs at half the $I C_{50}$ concentration. Images were captured at 0 and $24 \mathrm{~h}$ using a microscope (BOECO, Germany) coupled with the 5.0 Mega Cmos camera at the magnification of $4 \times$. Cell migration was determined by measuring the wound width using ImageJ software.

\section{Flow cytometry analysis of apoptosis}

Cells were plated in 6-well plates at $4 \times 10^{5}$ cells per well for T47D and MCF-7 cells and $3 \times 10^{5}$ cells per well for MDA-MB-231 cells. On the following day, cells were treated with either double $I C_{50}$ concentration of lansoprazole or doxorubicin as a positive control and incubated for $48 \mathrm{~h}$. Detached cells were collected, combined with the trypsinized attached cells, and centrifuged at $1400 \mathrm{RPM}, 4^{\circ} \mathrm{C}$, for $10 \mathrm{~min}$. The cell pellet was resuspended in 200 $\mu \mathrm{L}$ cold $1 \mathrm{X}$ binding buffer, and cells were stained with $5 \mu \mathrm{L}$ Annexin V-FITC and incubated for $5 \mathrm{~min}$ at room temperature. Propidium iodide was then added to each tube and analyzed immediately. The analysis was performed on BD FACSCanto II flow cytometer (BD Biosciences, USA) using BD FACSDiva software.

\section{Statistical analysis}

Data analysis was performed using GraphPad Prism software version 7. The differences between treatments groups were determined by $t$-test or one-way analysis of variance (ANOVA) followed by Tukey post hoc $t$-test as appropriate. Data were expressed as mean \pm SD and $p<0.05$ was considered a statistically significant difference. A non-linear regression analysis was used to calculate $I C_{50}$ values. The effect of combined treatment of 
PPIs and anticancer agents was evaluated by calculating the combination index (CI) value using CompuSyn software based on Chou-Talalay's Combination Index Theorem (21). CI values $<1,=1$, and $>1$ indicate synergism, additive, and antagonistic effects, respectively. $\mathrm{CI}$ values were calculated by using the following equation:

$$
\mathrm{CI}=(\mathrm{D} 1 / \mathrm{D} \times 1)+(\mathrm{D} 2 / \mathrm{D} \times 2)
$$

where $(\mathrm{Dx})_{1}=$ dose of drug 1 to produce $50 \%$ cell killing alone, $(\mathrm{D})_{1}=$ dose of drug 1 to produce $50 \%$ cell killing in combination with $(\mathrm{D})_{2},(\mathrm{Dx})_{2}=$ dose of drug 2 to produce $50 \%$ cell killing alone, and $(\mathrm{D})_{2}=$ dose of drug 2 to produce $50 \%$ cell killing in combination with (D) $)_{1}$.

\section{RESULTS AND DISCUSSION}

The effect of PPIs treatment on the migration of breast cancer cells

To examine the effect of PPIs on the migration of MDA-MB-231 cells, wound healing assay was performed. As can be noted in (Fig. 1a), complete closure of the wound was observed in the control sample. However, exposure to PPIs treatment significantly inhib-

a)

Control

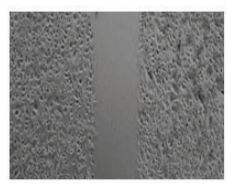

$0 \mathrm{~h}$

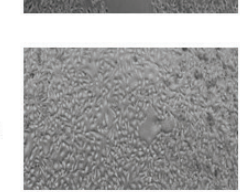

Lansoprazole
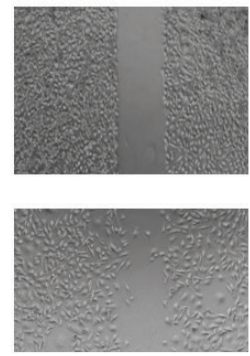

Omeprazole
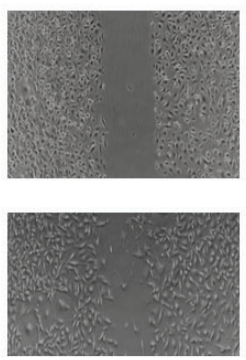

Pantoprazole
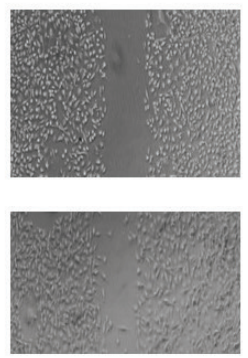

b)

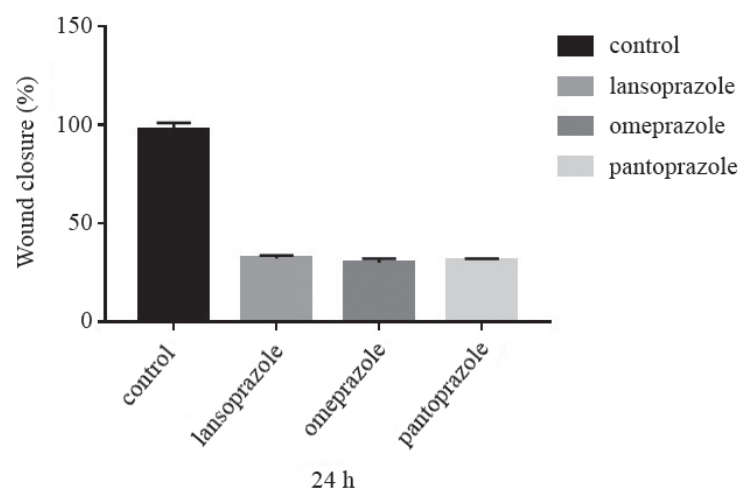

Fig. 1. Effect of PPIs treatment on MDA-MB-231 cells migration: a) images of the wound at the beginning and after $24 \mathrm{~h}$ of the treatment period (magnification $4 \mathrm{x}$ ); b) quantitative analysis of wound closure relative to wound distance at time 0 . The experiment was performed in duplicate and the data are expressed as mean $\pm \mathrm{SD} .{ }^{*} p>0.05$ significantly different from control group. 
ited the migration of MDA-MB-231 cells by 67, 69 and $68 \%$ for lansoprazole, omeprazole, and pantoprazole, respectively (Fig. 1b).

The V-ATPase expression is strongly associated with the invasive and metastatic capabilities of cancer cells. This was shown to be due to the acidic microenvironment that facilitates the optimal activation and secretion of proteases (22). Many studies have shown that breast cancer cells including MDA-MB-231, MCF-7, and T47D overexpress V-ATPases pumps. However, the activity of this pump appears to be augmented in highly metastatic cells like MDA-MB-231 relative to the poorly metastatic cells like MCF-7 (22, 23). Many pharmacological agents have been used as V-ATPase pump inhibitors like bafilomycin A1 and concanamycin. However, these agents exhibited high cytotoxicity to normal cells as well as to cancer cells. In contrast, PPIs are known to directly inhibit V-ATPase pumps and selectively target cancer cells (24).

\section{The antiproliferative effect of PPIs in different molecular subtypes of breast cancer}

The antiproliferative effects on different molecular subtypes of breast cancer cells treated with various doses of PPIs (lansoprazole, omeprazole, and pantoprazole) are shown in (Fig. 2). According to the results, the growth of breast cancer cells was significantly inhibited after PPIs treatment for $48 \mathrm{~h}$ compared to the control, in a dose-dependent manner. Interestingly, the observed antiproliferative effect of PPIs significantly varied between the three examined cell lines with T47D cells being the most responsive to PPIs treatment, whereas MDA-MB-231 cells were the least responsive cells. In contrast, the viability of normal fibroblast cells was not affected compared to the control group $\left(I C_{50}>3000\right.$ $\left.\mu \mathrm{mol} \mathrm{L}{ }^{-1}\right)$. On the other hand, lansoprazole appears to be more effective in cancer growth inhibition than omeprazole and pantoprazole. The $I C_{50}$ values for PPIs treatment were 129-299, 201-51 and 256-645 $\mathrm{mmol} \mathrm{L}^{-1}$ in T47D, MCF-7, and MDA-MB-231 cells, respectively (Table I).

Table I. The $50 \%$ inhibitory concentration $\left(\mathrm{IC}_{50}\right)$ for PPIs, doxorubicin, and raloxifene in different breast cancer cells

\begin{tabular}{lccc}
\hline & \multicolumn{3}{c}{$I_{50}\left(\mu \mathrm{mol} \mathrm{mL}^{-1}\right)^{\mathrm{a}}$} \\
\cline { 2 - 4 } & T47D & MCF-7 & MDA-MB-231 \\
\hline Lansoprazole & $129.0 \pm 9.8$ & $201.0 \pm 9.1$ & $256.5 \pm 4.3$ \\
Omeprazole & $222.4 \pm 8.8$ & $349.3 \pm 23.7$ & $395.6 \pm 7.2$ \\
Pantoprazole & $299.6 \pm 21.6$ & $514.4 \pm 25.9$ & $645.9 \pm 8.2$ \\
Doxorubicin & $1.9 \pm 0.2$ & $0.9 \pm 0.1$ & $2.0 \pm 0.2$ \\
Raloxifene & $27.3 \pm 1.9$ & $32.9 \pm 1.3$ & $25.0 \pm 2.1$ \\
\hline
\end{tabular}

${ }^{\mathrm{a}}$ mean $\pm \mathrm{SD}$

\section{PPIs enhanced apoptosis in breast cancer cells}

In order to determine if the anti-proliferative effect of PPI on the cells was due to the induction of apoptosis or necrosis, flow cytometric analyses of cells stained for annexin $\mathrm{V}$ or DNA fragmentation were performed. Following $48 \mathrm{~h}$ incubation period with the $I C_{50}$ con- 
a)

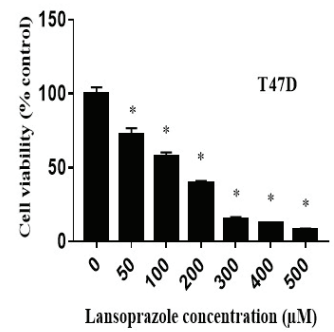

b)

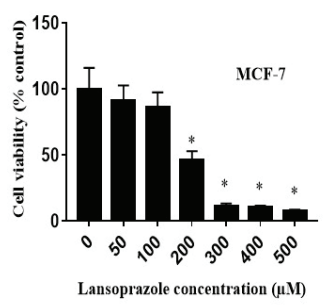

c)

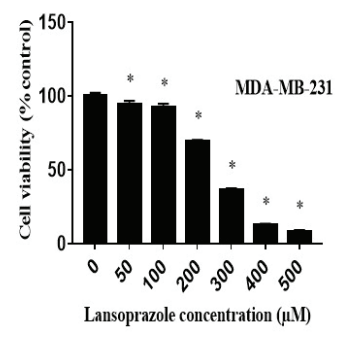

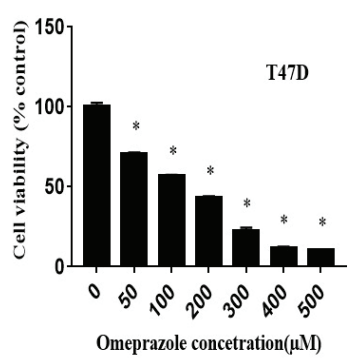
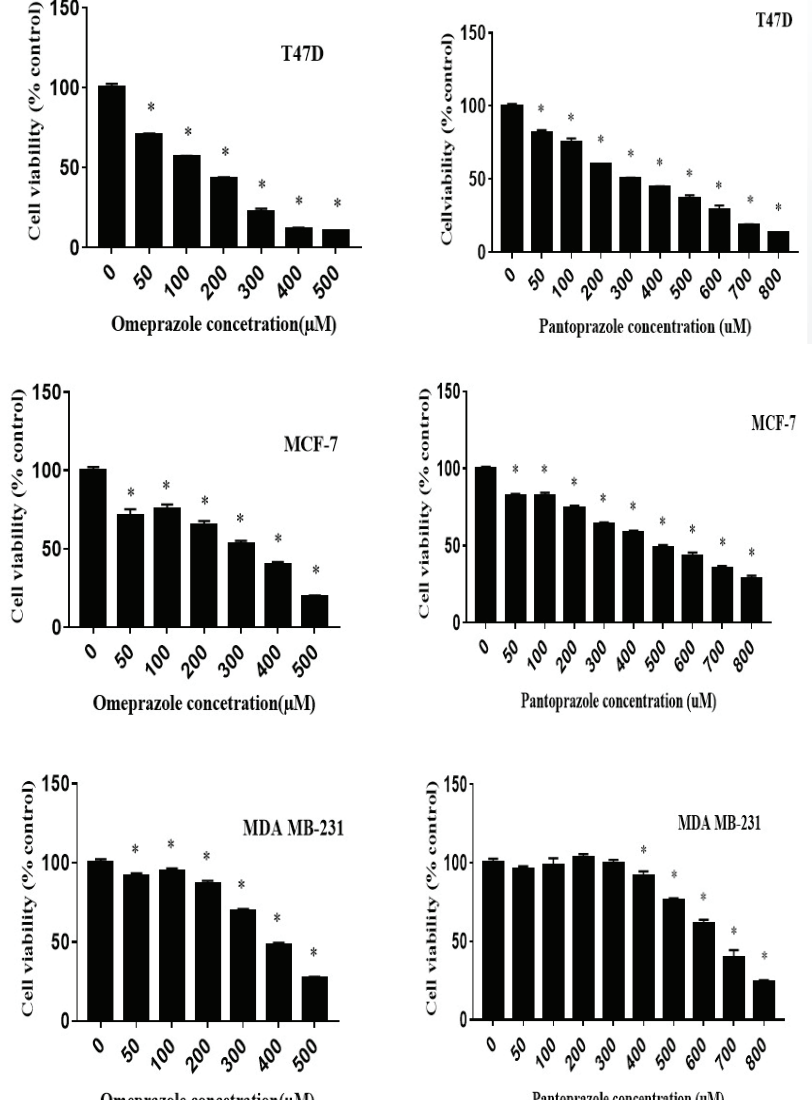

Fig. 2. Antiproliferative effects of PPIs treatment on cell viability of breast cancer cells in: a) T47D, b) MCF-7, c) MDA-MB-231. Data shown represent the mean percentages of cell viability \pm SD. Each experiment was performed in triplicate in three independent experiments $(N=3) .{ }^{*} p<0.05$ significantly different from control groups.

centration of lansoprazole, the percentages of apoptosis and necrosis were examined. As shown in (Fig. 3), exposure to PPIs significantly increased apoptosis by more than $50 \%$ in the three cell lines examined. On the other hand, the percentages of necrosis were not significantly affected.

According to De Milito et al. (25), omeprazole and esomeprazole showed an apoptotic effect in the human B cell line, which was mediated through a caspase-independent mechanism. In another study, by Scaringi et al. (26), omeprazole induced apoptosis in a time dosedependent manner in Jurkat cells (T-cells). In the latter cells, apoptosis was dependent on caspases and cysteine cathepsins. Interestingly, Zhang et al. (27), reported that lansoprazole significantly induced apoptosis in breast cancer cells through the ability to provoke cytosolic acidification, lysosomal alkalinization, and reactive oxygen species (ROS) accumulation. 
Further investigation into the different possible signaling pathways should shed light on the mechanism through which PPIs exert their apoptosis induction effect.

\section{Effects of combined treatment of PPIs and anticancer agents on the viability of breast} cancer cells

Doxorubicin is one of the most effective chemotherapeutic agents that is widely used in breast cancer treatment as well as for the treatment of other types of cancer such as lung, multiple myeloma, and thyroid cancers. It induces cytotoxicity effects through inhibition

a)

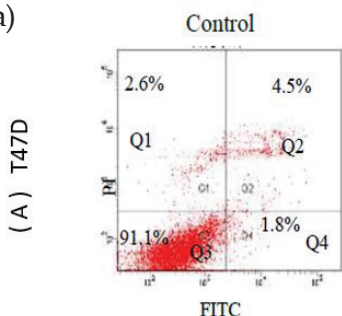

b)

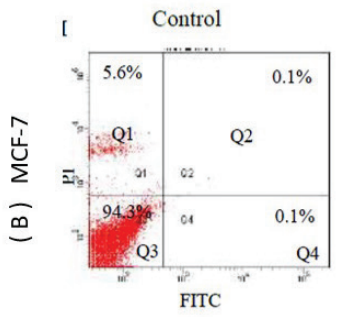

c)

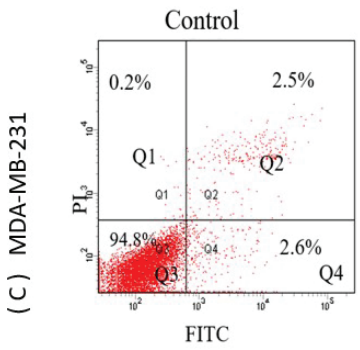

Lansoprazole

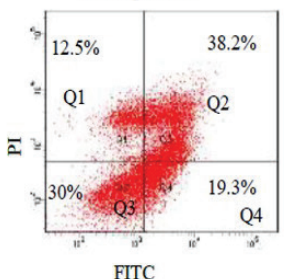

FITC

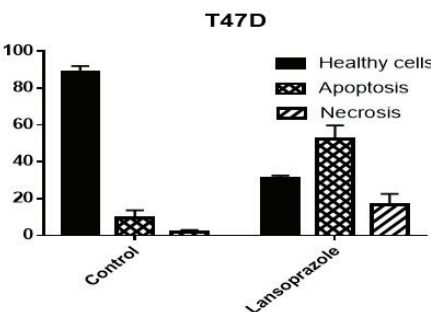

MCF-7
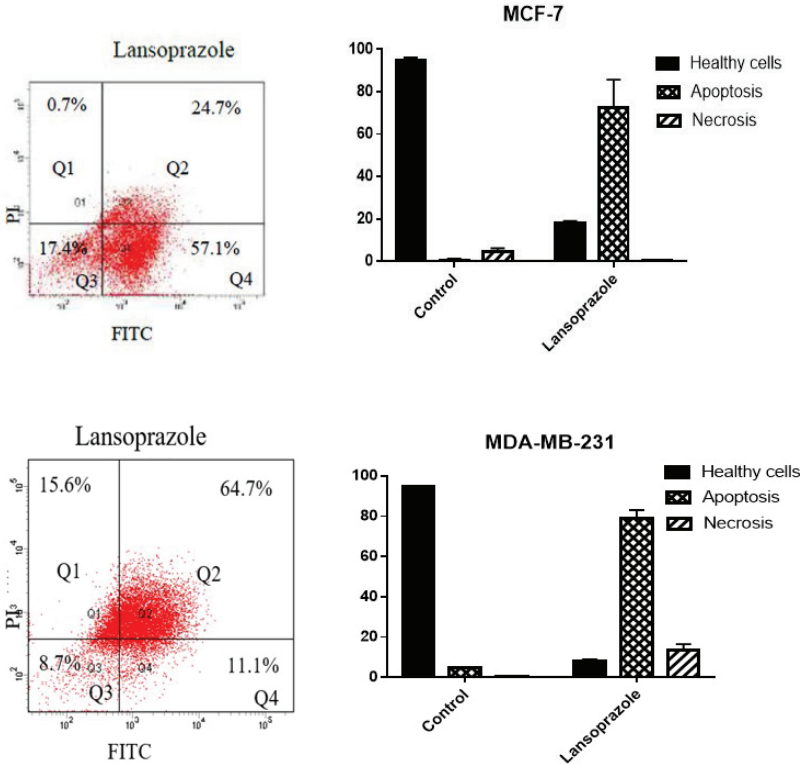

Fig. 3. Lansoprazole induces apoptosis in breast cancer cells. Breast cancer cells treated with lansoprazole for $48 \mathrm{~h}$ then stained with annexin V-FITC/ PI and analyzed by flow cytometry: a) dot plot for annexin V-FITC/ PI staining, where Q3 showed viable cells, Q1 necrotic cells, Q2 late apoptotic, and Q4 early apoptotic and percentages of alive cells, apoptotic cells and necrotic cells in T47D, b) MCF-7, c) MDA-MB-231. The experiment was performed in duplicate and the data are expressed as mean $\pm \mathrm{SD}$. 
of topoisomerase II or free radical generation. However, the cytotoxic effects of doxorubicin on various organs and tumor resistance limit its clinical usefulness (28). Patel et al. (29), reported that pretreatment with PPIs increased tissue penetration of doxorubicin in multilayered cell cultures and enhanced its distribution from blood vessels in solid tumors.

Raloxifene, on the other hand, is a second-generation selective estrogen receptor modulator (SERM) that induces estrogen antagonist effect on breast tissues (30). FDA has ap-

a)
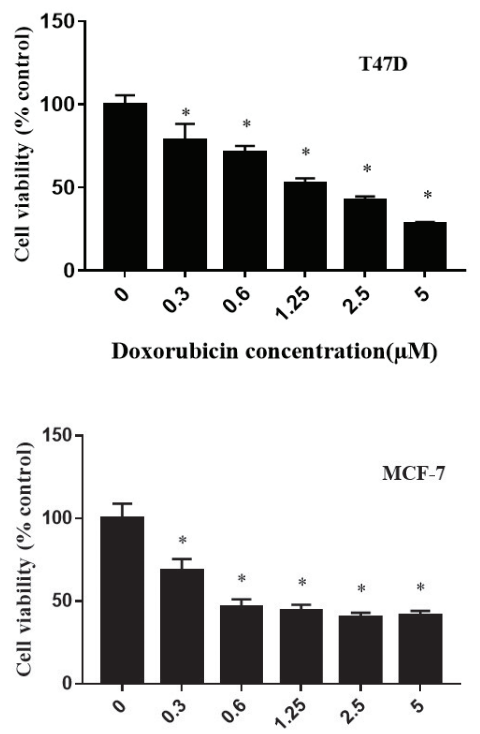

Doxorubicin concentration $(\mu \mathrm{M})$

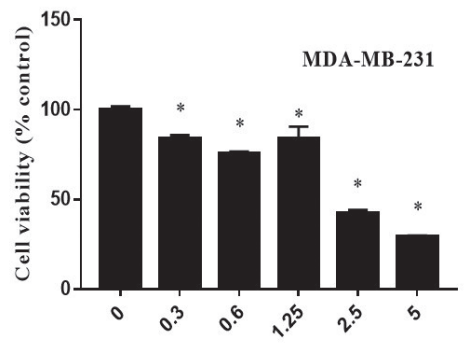

Doxorubicin concentration $(\mu \mathrm{M})$ b)

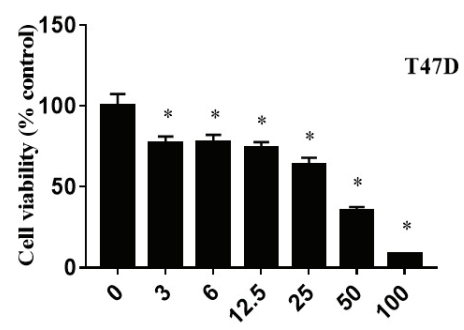

Raloxifene concentration $(\mu \mathrm{M})$

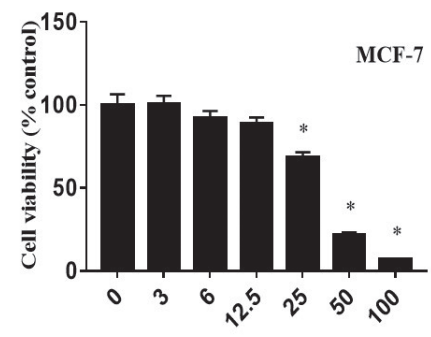

Raloxifene concentration $(\mu \mathrm{M})$

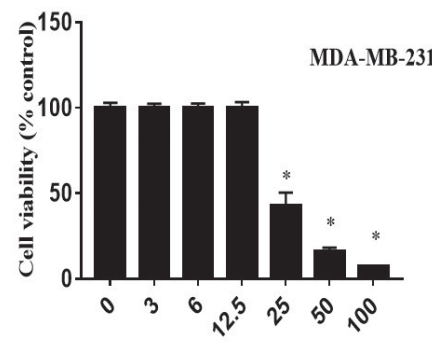

Raloxifene concentration $(\mu \mathrm{M})$

Fig. 4. Effect of anticancer agents on the growth of breast cancer cells: a) antiproliferative effects of doxorubicin treatment on cell viability of breast cancer cells, b) antiproliferative effects of raloxifene treatment on cell viability of breast cancer cells. Data shown represent the mean percentages of cell viability \pm SD. Each experiment was performed in triplicate in three independent experiments $(N=$ 3). ${ }^{*} p<0.05$ significantly different from control groups. 
proved raloxifene for the prevention and treatment of invasive ER-positive breast cancer in postmenopausal women. The beneficial role of combined treatment is the possibility to enhance the cytotoxic effect of chemotherapeutic agents by reducing the drug resistance and, consequently, allowing the use of lower concentrations of drugs while maintaining the same effectiveness.

The ability of PPIs to enhance the cytotoxic effects of the anticancer agents, doxorubicin and raloxifene, on breast cancer cells was then evaluated. First, the $I C_{50}$ of both drugs on the three cell lines were determined. Exposure of cells to increasing concentrations of doxorubicin ranged from 0.3 to $5 \mu \mathrm{mol} \mathrm{L}^{-1}$ significantly inhibited the growth of breast cancer cells in a dose-dependent manner (Fig. $4 \mathrm{a}$ ). The $I C_{50}$ values for doxorubicin were 1.9, 0.9 , and $2.0 \mu \mathrm{mol} \mathrm{L}{ }^{-1}$ in T47D, MCF-7, and MDA-MB-231 cells, respectively. Similarly, the survival of cells was significantly inhibited by raloxifene treatment at the concentration

a)
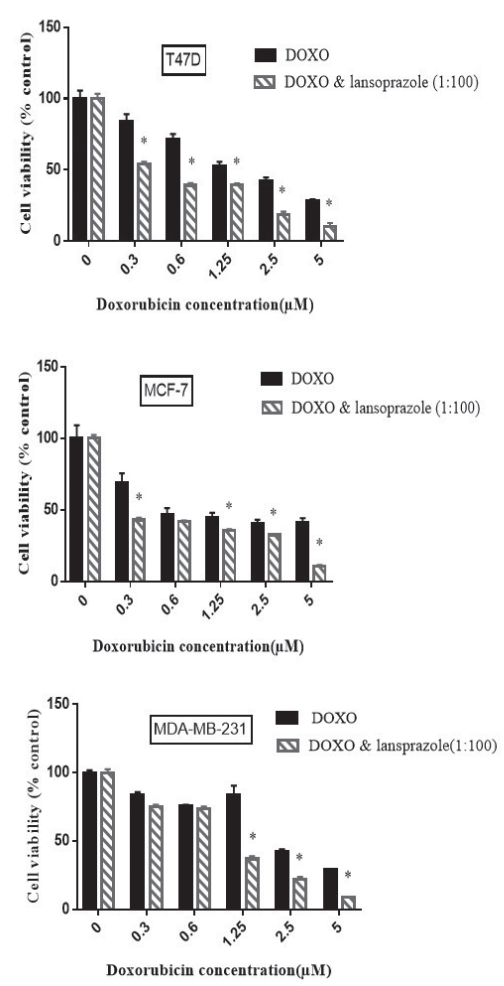

b)
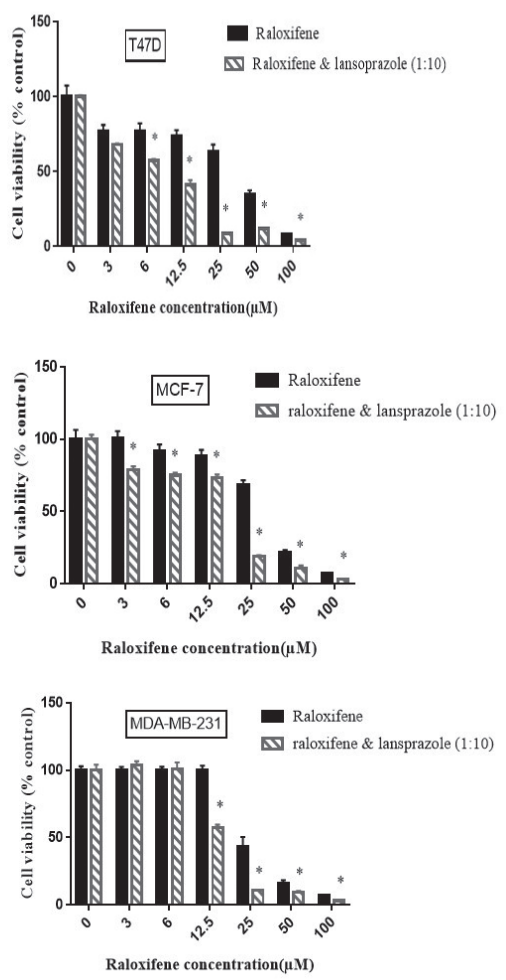

Fig. 5. Effect of combined treatment of lansoprazole and anticancer agents on the growth of breast cancer cells: a) effects of combined treatment of lansoprazole and doxorubicin on the growth of breast cancer cells after $48 \mathrm{~h}$ of treatment, b) effects of combined treatment of lansoprazole and raloxifene on the growth of breast cancer cells after $48 \mathrm{~h}$ of treatment. Data shown represent the mean percentages of cell viability \pm SD. Each experiment was performed in duplicate in three independent experiments $(N=3) .{ }^{*} p<0.05$ significantly different from respective anticancer agents treatment alone. 
W. G. Ihraiz et al.: Proton pump inhibitors enhance chemosensitivity, promote apoptosis, and suppress migration of breast cancer cells, Acta Pharm. 70 (2020) 179-190.

Table II. Combination index (CI) values for the combined treatment of PPIs and anticancer agents in breast cancer cell lines. $C I<1,=1$, and $>1$ indicate synergism, additive, and antagonistic effects, respectively

\begin{tabular}{lccc}
\hline \multirow{2}{*}{ Drug combination } & \multicolumn{3}{c}{ Combination index } \\
\cline { 2 - 4 } & T47D & MCF-7 & MDA-MB-231 \\
\hline Doxorubicin + Lansoprazole & 0.5 & 0.3 & 0.7 \\
Doxorubicin + Omeprazole & 0.4 & 0.3 & 0.7 \\
Doxorubicin + Pantoprazole & 0.6 & 0.2 & 0.5 \\
Raloxifene + Lansoprazole & 0.7 & 1.001 & 1.0 \\
Raloxifene + Omeprazole & 0.6 & 1.0 & 1.08 \\
Raloxifene + Pantoprazole & 0.7 & 1.07 & 1.09 \\
\hline
\end{tabular}

${ }^{*} p<0.05$ significantly different from respective anticancer agents treatment alone.

range 3-100 $\mu \mathrm{mol} \mathrm{L} \mathrm{L}^{-1}$ in a dose-dependent manner (Fig. $4 \mathrm{~b}$ ) with $I C_{50}$ values $27.3,32.9$, and $25.0 \mu \mathrm{mol} \mathrm{L}-1$ in T47D, MCF-7, and MDA-MB-231 cells, respectively. Our results demonstrated that the combination of PPIs and doxorubicin significantly increased the cytotoxic effect of doxorubicin and resulted in synergistic inhibition of growth in MDA-MB-231, MCF-7, and T47D cells $(\mathrm{CI}<1)$ (Table II). However, variable results were obtained when PPIs were combined with raloxifene. In T47D cells, combining PPIs to raloxifene significantly suppressed cell growth compared to respective raloxifene treatment alone with CI values $<1$. Interestingly, combined treatment of raloxifene and PPIs in MDA-MB-231 and MCF-7 cells rather demonstrate the additive effect. Thus, the combined effect of PPIs and anticancer drugs is variable and may be affected by the type of cancer cells, anticancer agents, and probably the mechanism that is responsible for drug resistance in the different cell lines.

\section{CONCLUSIONS}

PPIs (lansoprazole, omeprazole, and pantoprazole) inhibited the growth of MDAMB-231, MCF7, and T47D breast cancer cells in a dose-dependent manner. This anti-proliferative activity is mediated through the induction of apoptosis. Combined PPIs with doxorubicin resulted in synergistic inhibition of viability in three cell lines, but the combined effect with raloxifene induced a synergistic effect in T47D cells with only additive effect in MDA-MB-231 and MCF-7 cells. In MDA-MB-231 cells, PPIs treatment also significantly inhibited cell migration.

Acknowledgements. - We thank The Deanship of Academic Research at the University of Jordan for supporting this research.

\section{REFERENCES}

1. L. A. Torre, F. Bray, R. L. Siegel, J. Ferlay, J. Lortet-Tieulent and A. Jemal, Global cancer statistics, 2012, Ca-Cancer J. Clin. 65 (2015) 87-108; https://doi.org/10.3322/caac.21262

2. C. A. Gabriel and S. M. Domchek, Breast cancer in young women, Breast Cancer Res. 12 (2010) 212-221; https://doi.org/10.1186/bcr2647 
W. G. Ihraiz et al.: Proton pump inhibitors enhance chemosensitivity, promote apoptosis, and suppress migration of breast cancer cells, Acta Pharm. 70 (2020) 179-190.

3. G. Housman, S. Byler, S. Heerboth, K. Lapinska, M. Longacre, N. Snyder and S. Sarkar, Drug resistance in cancer: an overview, Cancers 6 (2014) 1769-1792; https://doi.org/10.3390/cancers6031769

4. M. A. Aleskandarany, M. E. Vandenberghe , C. Marchiò , I. O. Ellis, A. Sapino and E. A. Rakha, Tumour heterogeneity of breast cancer: from morphology to personalized medicine, Pathobiology 85 (2018) 23-34; https://doi.org/10.1159/000477851

5. S. Fais, G. Venturi and B. Gatenby, Microenvironmental acidosis in carcinogenesis and metastases: new strategies in prevention and therapy, Cancer Metastasis Rev. 33 (2014) 1095-1108; https://doi. org/10.1007/s10555-014-9531-3

6. E. K. Rofstad, B. Mathiesen, K. Kindem and K. Galappathi, Acidic extracellular pH promotes experimental metastasis of human melanoma cells in athymic nude mice, Cancer Res. 66 (2006) 6699_ 6707; https://doi.org/10.1158/0008-5472.can-06-0983

7. S. Taylor, E. P. Spugnini, Y. G. Assaraf, T. Azzarito, C. Rauch and S. Fais, Microenvironment acidity as a major determinant of tumor chemoresistance: Proton pump inhibitors (PPIs) as a novel therapeutic approach, Drug Resist. Updates 23 (2015) 69-78; https://doi.org/10.1016/j.drup.2015.08.004

8. M. Bellone, A. Calcinotto, P. Filipazzi, L. Rivoltini, A. De Milito and S. Fais, The acidity of the tumor microenvironment is a mechanism of immune escape that can be overcome by proton pump inhibitors, OncoImmunology 2 (2013) e22058; https://doi.org/10.4161/onci.22058

9. D. A. Loeffler, P. L. Juneau and G. H. Heppner, Natural killer- cell activity under conditions reflective of tumor micro-environment, Int. J. Cancer 48 (1991) 895-899; https://doi.org/10.1002/ijc.2910480617

10. S. Fais, A. De Milito, H.You and W.Qin, Targeting vacuolar H+-ATPases as a new strategy against cancer, Cancer Res. 67 (2007) 10627-10630; https://doi.org/10.1158/0008-5472.CAN-07-1805

11. C. A. Stedman and M. L. Barclay, Review article: comparison of the pharmacokinetics, acid suppression and efficacy of proton pump inhibitors, Aliment. Pharmacol. Ther. 14 (2000) 963-978; https://doi. org/10.1046/j.1365-2036.2000.00788.x

12. K. Lindner, C. Borchardt, M. Schopp, A. Burgers, R. Hummel, C. Stock, D. J. Hussey and J. Haier, Proton pump inhibitors (PPIs) impact on tumour cell survival, metastatic potential and chemotherapy resistance, and affect expression of resistance-relevant miRNAs in esophageal cancer, Exp. Clin. Cancer Res. 33 (2014) 73-85; https://doi.org/10.1186/s13046-014-0073-x

13. J. Patlolla, Y. Zhang, Q. Li, V. Steele and C. Rao, Anti-carcinogenic properties of omeprazole against human colon cancer cells and azoxymethane-induced colonic aberrant crypt foci formation in rats, Int. J. Oncol. 40 (2012) 170-175; https://doi.org/10.3892/ijo.2011.1214

14. A. Udelnow, A. Kreyes, S. Ellinger, K. Landfester, P. Walther, T. Klapperstueck, J. Wohlrab, D. HenneBruns, U. Knippschild and P. Würl, Omeprazole inhibits proliferation and modulates autophagy in pancreatic cancer cells, Plos One 6 (2011) e20143; https://doi.org/10.1371/journal.pone.0020143

15. M. Yeo, D. K. Kim, Y. B. Kim, T. Y. Oh, J. E. Lee, S. W. Cho, H. C. Kim and K. B. Hahm, Selective induction of apoptosis with proton pump inhibitor in gastric cancer cells, Clin. Cancer Res. 10 (2004) 86878696; https://doi.org/10.1158/1078-0432.CCR-04-1065

16. U. H. Jin, S. O. Lee, C. Pfent and S. Safe, The aryl hydrocarbon receptor ligand omeprazole inhibits breast cancer cell invasion and metastasis, BMC Cancer 14 (2014) 498; https://doi.org/10.1186/14712407-14-498

17. Y. Shen, M. Chen, S. Huang and M. Zou, Pantoprazole inhibits human gastric adenocarcinoma SGC7901 cells by downregulating the expression of pyruvate kinase M2, Oncol. Lett. 11 (2016) 717-722; https://doi.org/10.3892/ol.2015.3912

18. X. Zeng, L. Liu, M. Zheng, H. Sun, J. Xiao, L. Lu, G. Huang, P. Chen, J. Zhang, F. Zhu, H. Li and Q. Duan, Pantoprazole, an FDA-approved proton-pump inhibitor, suppresses colorectal cancer growth by targeting T-cell-originated protein kinase, Oncotarget 7 (2016) 22460-22473; https://doi.org/ 10.18632/oncotarget.7984

19. M. Chen, S. L. Huang, X. Q. Zhang, B. Zhang, H. Zhu, V. W. Yang and X. P. Zou, Reversal effects of pantoprazole on multidrug resistance in human gastric adenocarcinoma cells by down-regulating 
the V-ATPases/mTOR/HIF-1a/P-gp and MRP1 signaling pathway in vitro and in vivo, J. Cell. Biochem. 113 (2012) 2474-2487; https://doi.org/10.1002/jcb.24122

20. S. K. Bardaweel, H. A. Alsalamat, S. M. Aleidi and R. M. Bashatwah, Glucose deprivation enhances the antiproliferative effects of oral hypoglycemic biguanides in different molecular subtypes of breast cancer: An in vitro study, Acta Pharm. 68 (2018) 517-524; https://doi.org/10.2478/ acph-2018-0031

21. T. C. Chou, Theoretical basis, experimental design, and computerized simulation of synergism and antagonism in drug combination studies, Pharmacol. Rev. 58 (2006) 621-681; https://doi. org/10.1124/pr.58.3.10

22. S. R. Sennoune, K. Bakunts, G. M. Martínez, J. L. Chua-Tuan, Y. Kebir, M. N Attaya and R. Martínez-Zaguilán, Vacuolar H+-ATPase in human breast cancer cells with distinct metastatic potential: distribution and functional activity, Am. J. Physiol. Cell Physiol. 286 (2004) C1443-C1452; https://doi.org/10.1152/ajpcell.00407.2003

23. J. Capecci and M. Forgac, The function of vacuolar ATPase (V-ATPase) a subunit isoforms in invasiveness of MCF10a and MCF10CA1a human breast cancer cells, J. Biol. Chem. 288 (2013) 3273132741; https://doi.org/10.1074/jbc.M113.503771

24. E. Iessi, M. Logozzi, D. Mizzoni, R. Di Raimo, C. Supuran and S. Fais, Rethinking the combination of proton exchanger inhibitors in cancer therapy, Metabolites 8 (2018) 2; https://doi.org/10.3390/ metabo8010002

25. A. De Milito, E. Iessi, M. Logozzi, F. Lozupone, M. Spada, M. L. Marino, C. Federici, M. Perdicchio, P. Matarrese, L. Lugini, A. Nilsson and S. Fais, Proton pump inhibitors induce apoptosis of human B-cell tumors through a caspase-independent mechanism involving reactive oxygen species, Cancer Res. 67 (2007) 5408-5417; https://doi.org/10.1158/0008-5472.CAN-06-4095

26. L. Scaringi, P. Cornacchione, E. Ayroldi, L. Corazzi, E. Capodicasa, R. Rossi and P. Marconi, Omeprazole Induces apoptosis in jurkat cells, Int. J. Immunopathol. Pharmacol. 17 (2004) 331-342; https://doi.org/10.1177/039463200401700313

27. S. Zhang, Y. Wang and S. J. Li, Lansoprazole induces apoptosis of breast cancer cells through inhibition of intracellular proton extrusion, Biochem. Biophys. Res. Commun. 448 (2014) 424-429; https://doi.org/10.1016/j.bbrc.2014.04.127

28. C. Cristina, X. S. Renato, C. Susana, C. Sonia, J. O. Paulo, S. S. Maria and I. M. Paula, Doxorubicin: the good, the bad and the ugly effect, Curr. Med. Chem. 16 (2009) 3267-3285; https://doi.org/10.2174/ 092986709788803312

29. K. J. Patel, C. Lee, Q. Tan and I. F. Tannock, Use of the proton pump inhibitor pantoprazole to modify the distribution and activity of doxorubicin: a potential strategy to improve the therapy of solid tumors, Clin. Cancer Res. 19 (2013) 6766-6776; https://doi.org/ 10.1158/1078-0432.CCR-130128

30. J. R. Rey, E. V. Cervino, M. L. Rentero, E. C. Crespo, A. O. Álvaro and M. Casillas, Raloxifene: mechanism of action, effects on bone tissue, and applicability in clinical traumatology practice, Open Orthop. J. 3 (2009) 14-21; https://doi.org/10.2174/1874325000903010014 